\title{
An Informal Approach to Identify Bright Graduate Students by Evaluating their Classroom Behavioral Patterns by Using Kohonen Self Organizing Feature Map
}

\author{
C.Bhanuprakash \\ Department of Master of Computer Applications, Siddaganga Institute of Technology, Tumkur, India. \\ Email: bhanuprakashc@hotmail.com \\ Y.S. Nijagunarya \\ Department of Computer Science and Engineering, Siddaganga Institute of Technology, Tumkur, India. \\ Email: nijagunarya@yahoo.com \\ M.A. Jayaram \\ Department of Master of Computer Applications, Siddaganga Institute of Technology, Tumkur, India. \\ Email: jayaramdps@gmail.com
}

Received: 02 May 2018; Accepted: 13 July 2018; Published: 08 August 2018

\begin{abstract}
The intention of this paper is to analyze how a behavior of a student will influence us in gauging their performance level rather than considering their traditional examination scores. This approach is considered to be one of the informal approaches which guide many school managements to identify good, average and poor category of students. The main criteria used here is behavioral science which explores activities and interactions among the student community when they are inside the school campus.

School-Wide Positive Behavior Support can assist in addressing the issues related to the prevention, educational identification and effective intervention implementation through its systemic logic, data-based decision making, and capacity building within and across schools.

Clustering is the process of grouping a set of data objects into multiple groups or clusters with high similarities and dissimilarities. Dissimilarities and Similarities are assessed on the attribute values describing the objects and often involve distance measures. Clustering acts as a data mining tool by having its roots in many application areas such as biology, security, business intelligence, web search etc.

In this survey, we have involved $200+$ students who are currently studying engineering streams in various classes that includes first semester to final semester. Their age group was in the range of 18 to 22 years. Their behavioral survey has been conducted over a span of 4 to 6 months by closely observing their activities, mannerisms and then evaluated by entering in to this system by using the evaluation interface. This evaluation interface consists of 15 features with 4 optional choices.
\end{abstract}

Each choice is rated with a specific numeric value. By taking one of the choices among all the 15 features for each of the student, at the end, he/she will get some score which will be stored in a database. With the help of this score, a manual grouping was done. Later, for the same dataset, a soft computing technique has been applied by working with self organizing feature map algorithm for grouping the students.

Index Terms-Clustering, Self Organizing Map, Behavioral Science, Range of values, Fuzzy predicates, Similarities, Neural networks, Hidden layers, feedback.

\section{INTRODUCTION}

In our traditional education system, the educational experts have formulated many rules and regulations for the courses which are running in universities and their related educational institutions. Here, a student has to study by joining a course, appearing examinations and scored some amount of marks. Many experts have considered this marks as main criteria to gauge his/her performance. This is the formal procedure that a common person has to follow in almost every place. But, in this paper, it has been proposed an informal approach to identify the bright students without considering their academic examination performance; instead, it is considered their classroom behavior. In this regard, a thorough survey has been conducted on graduate students of 5 to 6 different classes. Here, survey has been conducted on nearly $235+$ students by closely observing their day to day behaviors when they are attending the 
classes, especially when they are sitting in a classroom. Some of the features considered here are - place of sitting, regularity of attendance, frequency of asking questions, taking tips of notes, activeness of a student, time punctuality of a student, point of eyesight of a student, tendency towards absent mind, respect to the teacher, listening, writing, thinking, speaking ability of a student, tendency towards sleeping and dressing sense of a student. All these features have been closely exercised on each and every student. A small database application has been developed with some interfaces. One of the interfaces has got all the above features which seem like online evaluation sheet. Each feature is assigned with a proper rated numerical value. At the end of the evaluation for all the 15 features, total rate will be automatically calculated and stored in a database. Depending on this total rated value, a grade will be found. This interface will be given to the person who will evaluate the student behavior in a classroom. This is usually done by a teacher / lecturer / professor / tutor who are taking classes to graduate students and observing their behaviors nearly over a minimum span of 6 to 8 months. This procedure was repeated for all the students for a given class. This procedure has been repeated for 6 graduate classes i.e. nearly 235 + students. At the end of online evaluation, one more interface was given with the list of rated numerical values for all the students. A manual grouping was done based on range of values fixed in a traditional manner. Later the period, for the same dataset, it has been applied with self organizing feature map algorithm (SOFM) by using Mat-lab tool to cluster the students. At the end, it was found that, there was a slight variation in number of students belongs to each group in both manual method and soft computing method. This has given us a new idea in identifying group of bright students in an informal way not only by considering their academic results rather than classroom behavior. This will really help many institutes' management in guiding how to take proper measures to help weak students and to promote bright students to further improve their academic results. This is the prime concern of this paper.

\section{RELATED WORK}

There have been many approaches made by educational experts on student's behavior by considering varied aspects. Many of the experts made their thorough research on students range from primary school to higher degree." Student's Perceptions of Classroom Behavior Problems and the Effectiveness of Different Disciplinary Methods" [1]. Here, the main purpose was to examine students' perceptions of troublesome behavior and the effectiveness of different disciplinary methods. They did a survey by including nearly 350 primary school students. At the end, it was concluded that both teachers and students need to be educated and effective management strategies can be developed and used by teachers.

"Classroom Management: A Critical Part of Educational Psychology, With Implications for Teacher
Education" [2]. Here, research was focused mainly on classroom management with an emphasis on educational psychology with implications for teacher education. Preventive group based approaches have been proposed to a school management which provide a basis for teachers to plan and organize classroom activities and behaviors. They provide additional perspectives on teacher's progress and also on the factors that influence school management.

"Classroom Management in Inclusive Settings"[3]. Here, the focus was mainly on the children with disabilities. This has given an opportunity for teachers to identify classroom management policies and practices that promote community building management strategies which facilitate friendships, parent involvement, collaborations and address challenging behaviors in a positive manner.

"Assessment and Classroom Learning"[4]. Here, the research was mainly on the review of the literature on classroom formative assessment. It has shown them a firm evidence that innovations designed to strengthen the learning attitudes of the students. The perceptions of students and their role in self - assessment are considered along with strategies used by teachers. It follows a more detailed and theoretical analysis of the nature of feedback which provides a basis for a discussion of the development of theoretical models for formative assessment and of the prospects for the improvement of practice.

"Factors influencing students' learning approaches in auditing"[5]. Here, research was mainly aims to reveal an investigation to understand factors influencing students learning approaches in the discipline of auditing. This was followed by focus group discussions to obtain a deeper understanding of the factors that influenced the ways their audit studies were approached. Statistical analysis revealed that gender and race influenced students' learning approaches at specific levels. The data are drawn from audit students at a residential university. The study extends the existing student learning literature by adding perspectives from the discipline auditing. It could stimulate educators' scholarly interest in pedagogic research which could contribute to curriculum and teaching method changes that equip audit educators to promote deep learning.

Here, it has been considered all these works as a basis for further research on classroom behaviours of graduate students. This is one of the sincere attempts made in this regard to identify bright students which aid the management of many schools and colleges so that they can design their own classroom curriculum activities in a most appropriate ways.

\section{METHODOLOGY}

It is suggested to use the following steps :

Identifying proper graduate classes where diversity of students were found. 
a) Identifying and analyzing classroom behavioral features / attributes for evaluating student's classroom behavior.

b) Designed and developed a small database application which has got some interfaces and result reports.

c) Extraction of data set from this database application in a form of Excel Sheet.

d) Preprocessing this dataset for cluster analysis by copying dataset from excel sheet and load into mat-lab tool for further processing.

e) Manual grouping was done by making of range of grade rating values.

f) By using tools (Mat lab, R tool), run the data set and compare the result with manual grouping set.

\subsection{Collection of Features/attributes considered for} behavior analysis:

There has been a small database application with a name "Evaluation of Classroom Behavior of a Student" was developed to enter the classroom behavioral facts of the students. This application has got 6 interface forms to enter the required data to the database.

The first interface shown in Fig. 1 is used to enter the student details in to this database application. This can be done on the basis of class wise. Here, StudentId will be generated automatically in a unique way, followed by student name, followed by Student's USN number which was given by the Visveswaraya Technological University and ends with current semester.

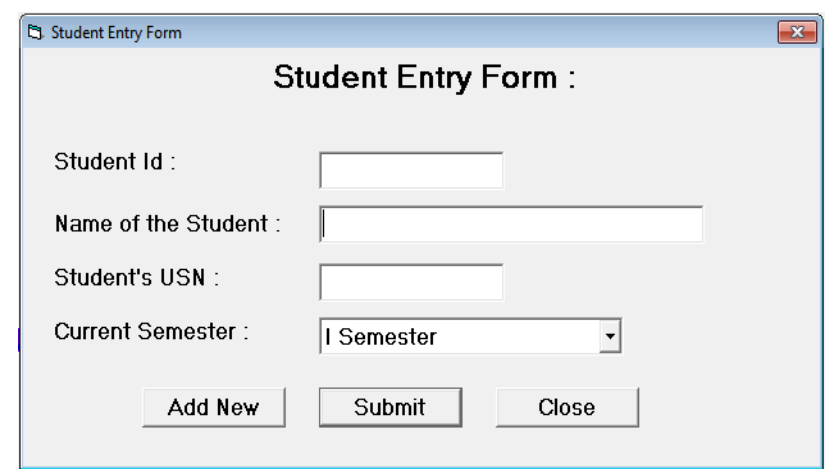

Fig.1. Interface form to enter new student details in to the database

The second interface shown in Fig. 2 is used to list out the semester wise student details from the database. This will give us a small details of all the students for a particular semester that includes SINo, StudentId, StudentName and USN.

The third interface is shown in the Fig.3. This interface has 15 features. Each feature has got 4 alternative options. A user has to choose 1 out of the 4 options. For the effective analysis, it is advisable to opt for all the 15 features to every student for a given class. Each of the option is rated with a fixed numerical value. i.e. option-A is fixed with 4.75 , option-B is fixed with 3.5 , option-C is fixed with 2.25 and option-D is fixed with 1.25.

After assigning a numerical value to all the options for 15 features, the overall points will be calculated as follows.
$4.75 \times 15=71.25$. If a student scores 71.25 , then his score will be considered as $100 \%$. Based on this value, a range of values have been fixed to allocate the students to a particular group.

\begin{tabular}{|c|c|c|c|c|}
\hline \multicolumn{4}{|c|}{ Dist of Semester Students: } & $-x$ \\
\hline \multicolumn{5}{|c|}{ List of Students : } \\
\hline \multicolumn{5}{|c|}{ Semester : III Semester } \\
\hline SI No & Studentld & StudentName & USN & $\Delta$ \\
\hline 1 & STD114 & Abhijith H.G & 1SI16MCA01 & \\
\hline 2 & STD115 & Abhishek Gowda M & 1S116MCAO2 & \\
\hline 3 & STD116 & Achyuthakrishna Hebbar $\mathrm{K}$ & 1SI16MCAO3 & \\
\hline 4 & STD117 & Anushree $\mathrm{s}$ & 1SI16MCAO4 & \\
\hline 5 & STD118 & Archana P & 1SI16MCA05 & \\
\hline 6 & STD119 & Bhanukumar K.R & 1SI16MCAO6 & \\
\hline 7 & STD120 & Chaitra B.M & 1S116MCAO7 & \\
\hline 8 & STD121 & Chaitrashree M.N & 1SI16MCA08 & \\
\hline 9 & STD122 & Chaitra M.P & 1S116MCA09 & \\
\hline 10 & STD123 & Chandan & 1S116MCA10 & \\
\hline 11 & STD124 & Deepa G.J & 1SI16MCA11 & \\
\hline 12 & STD125 & Deepu N & 1SI16MCA12 & \\
\hline 13 & STD126 & Geetha T.K & 1SI16MCA13 & \\
\hline 14 & STD127 & H.Aruna & 1SI16MCA14 & \\
\hline 15 & STD128 & Jyothi J & 1SI16MCA15 & \\
\hline 16 & STD129 & Kokila D.R & 1SI16MCA16 & \\
\hline 17 & STD130 & Lakshmi K & 1SI16MCA17 & \\
\hline 18 & STD131 & Manoj H.G & 1SI16MCA18 & -1 \\
\hline$\cdots$ & $\cdots$ & Close & & \\
\hline
\end{tabular}

Fig.2. Interface form to list out semester wise student details

\subsubsection{Place of Sitting}
a) Front rows
b) Middle rows
c) Side rows
d) Last rows

This feature will indicate the place where the student is sitting in a class room. Generally, the sincere, obedient and intelligent students preferably want to sit either at the front rows or at the middle rows, but not at the last rows. The students who want to attend the classes for the sake of getting attendance will usually sit at the last rows.

\subsubsection{Frequency of asking questions}
a) Frequently with genuine questions
b) Occasionally with genuine questions
c) Occasionally with silly questions
d) Never asking any questions

This feature will indicate the concentration, attention and focus of the students towards the teacher as well as the subject. The student who is eager to learn the things about the subject is always focusing on the subject as well as the teacher and tries to ask the genuine questions very frequently. The average students will ask the questions on rare occasions. Some category of students will ask silly questions just for the sake of their identity in a class room. i.e. attracting others towards them. But below average students will never ask any sort of questions. 


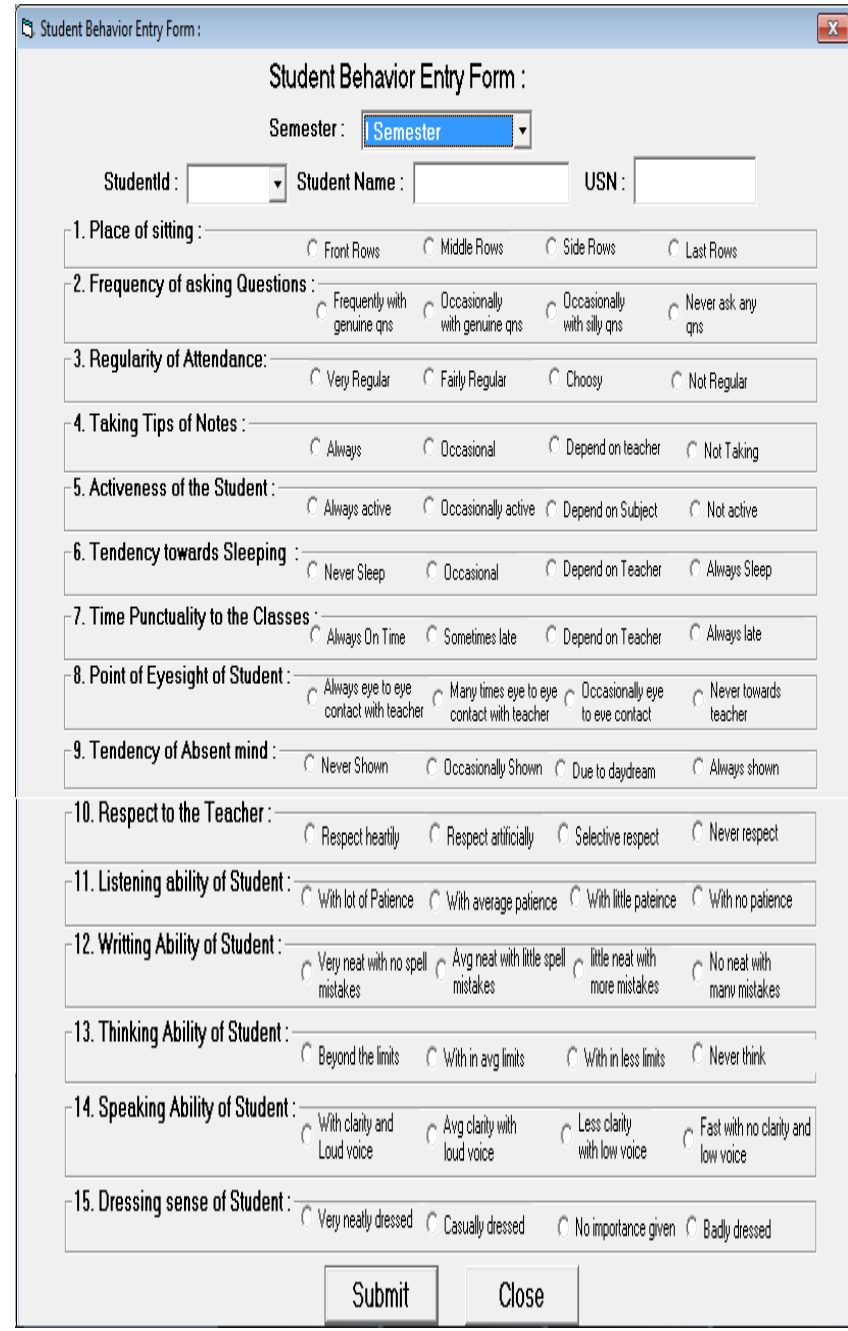

Fig.3. Interface form to Evaluate classroom behavior of a student

\subsubsection{Regularity of attendance}
a) Very regular
b) Fairly regular
c) Choosy
d) Not regular

This feature will indicate the regularity of students in attending the classes. The better student will try to attend almost all the classes, only on the rare occasions, with the genuine reasons, they may miss the classes. Some students may attend the classes not so regularly, but they may get moderate attendance since they are not much specific about the attendance. Some category of students is very choosy in attending the classes. This depends on varied reasons that include the quality of teaching, his fluency of language, his subject knowledge, his way of approaching the students. If a teacher is weak with all these points, then this category of students will be very choosy in attending such classes. The below average students who are not serious about the studies will be very irregular. Even though, the teacher is good, subject is interesting, they are not attending the classes regularly.

\subsubsection{Taking tips of notes}
a) Always
b) Occasional
c) Depend on teacher
d) Not taking

This feature will indicate the taking tips of notes. i.e. while listening the lecture class from a teacher, he may write so many topic related important things on the black board. Generally, it is a tendency of a bright student will take all those points to their personal notebook. This habit will influence the student vision towards the topic of subject very much. But don't expect the same attitude from every student. Some student will take the notes only at the rare occasions and some category of students will never take any of the tips, since they are forcibly sitting in the class just for the sake of getting attendance.

\subsubsection{Activeness of a student}
a) Always active
b) Occasionally active
c) Depend on subject
d) Not active

This feature will indicate the activeness of a student while he / she is there with his / her peers inside the class room. Some kind of the students is having the good energy level throughout the day. They are very much active in almost all the academic activities. Being a bright student, this is one of the prime features to consider. But in a real time situation, we will be getting only nominal number of this kind. Many time, many of the students do not having activeness and energy in a class room which implies their uninteresting towards all their academic activities.

\subsubsection{Tendency towards sleeping :}
a) Never sleep
b) Occasionally sleep
c) Depend on teacher
d) Sleeping at many times

This feature will indicate the activeness of a student in a class room. Some kind of the students is having the good energy level throughout the day, they are very much active and they never sleep during the class hours. But some category of students, because of their uninteresting towards the subject and teacher, unknowingly they went to sleep at many of the occasions. Sometimes if the classes will be conducted after the lunch hours, if the subject is of theory type, that definitely leads the student to sleep. In addition to these, some group will be always in sleeping mode irrespective of the subject, teacher and time.

\subsubsection{Time Punctuality to the classes:}
a) Always on time
b) Sometimes late
c) Depend on teacher
d) Always late 
This feature will indicate how much importance will be given by the student regarding the incoming time. Good students are always giving much importance to the class timings, especially incoming time and strictly they are adhere to that. Some kind of the students is showing their ignorance and they are almost coming late to every classes, many times after arrival of the teacher. This also depends on the type of the teacher. If he is too strict, then it implies forcible time constraints on the students.

\subsubsection{Point of Eyesight of the student with teacher}

a) Always eye to eye contact

b) Many times eye to eye contact

c) Occasionally eye to eye contact

d) Never towards teacher

This feature will indicate how actually a student can sit and concentrate inside the class room while listening to the class lectures. A studious student is always having eye to eye contact with teacher. This is an indication that every expert says that a student is patiently listening to the teacher with at most concentration. If it deviates slightly to the other side, it is an indication that there is a slight disturbance in the concentration. i.e. the focus of the student is always observed by looking eyesight of the student.

\subsubsection{Tendency of absent mind.}
a) Never shown
b) Occasionally shown
c) Due to daydream
d) Always shown

This feature will indicate how actually a student can concentrate in the class room. A studious student is always having presence of mind and focusing towards the topic taught by the teacher. Some of the students may physically present and mentally thinking somewhere else. The other group of the students is always having a daydream about many things and they are totally away from the classroom activities. One more category is always showing absence of mind, because they joined the course either with willingness of their parents or advise from their friends. They cannot focus on the teacher, since they don't have that practice.

\subsubsection{Respect to the teacher:}
a) Respect heavily
b) Respect artificially
c) Selective respect
d) Never respect

This feature will indicate how a student respects the teacher. A studious student is always shows high respect to the teacher. Sometime he may consider some teachers as their role model and they follow their guidelines. Some group of the students may show respect to the teachers forcibly, like artificial type, but that is not from their heart. The other group of the students may show respect only to certain teachers, not all the teachers. It is like selective type. Sometimes this is not fair enough as a part of being a student. In addition to these, one more category of students never shows any kind of the respect towards the teacher, but the percentage of this tendency is always minimum.

\subsubsection{Listening ability of the student:}

a) With lot of patience

b) With average patience

c) With little patience

d) With no patience

This feature will indicate how a student can able to listen the concepts taught by the teacher. This depends on the degree of the language familiarity to the student. Generally, English is the common language used for class room teaching. If a student is having enough vocabulary of words over English language, then it is easy for him to understand the concepts. The studious students are always having good listening ability skills and they are always keeps their focus on the words delivered by the teacher with enough patience. Some category of the students may have good listening ability but they may be lack in their concentration. The other category of students are suffering from the problem in listening itself, which creates some sort of ambiguity in getting many words which in turn results in lack of patience. One more group of students do not have any sort of patience which creates a problem to listening. This is due to varied reasons.

\subsubsection{Writing ability of the student:}

a) Very neat with no spell mistakes

b) Average neat with less spell mistakes

c) Little neat with more spell mistakes

d) No neat with many spell mistakes

This feature will indicate how a student can able to write the things on the paper. This depends on the extent to which a student is having the knowledge on the language vocabulary and its grammar. Generally, the studious students are always having good writing ability skills and they keep on writing in a very neat manner without any spelling mistakes. Some category of the students may have good writing ability skills, but they may be lack in their language vocabulary of words which results in spelling mistakes. The other category of students are suffering from the problem in writing itself, which creates some sort of ugliness and many spelling mistakes. One more group of students do not have any sort of patience in writing the things on the paper. They are very poor at writing. They do lot of spelling mistakes and they ignore neatness.

\subsubsection{Thinking ability of the student:}
a) Beyond the limits
b) Within average limits
c) Within less limits
d) Never think 
This feature will indicate how a student can able to interpret the concepts taught by the teacher. This depends on the degree of thinking ability of the student. If a teacher raised a question, then some students can able to tell the answer by thinking within the limits and others can think beyond the limits. This depends on the extent to which they are having the knowledge on the related subject. If a student is having strong knowledge, then he may try the question by thinking beyond the limits. Some category of the students may have good thinking ability but they may be lack in interpretation and they may go with in the limits. The other category of students will never think and they may be failed in finding the answer. This is once again due to varied reasons.

\subsubsection{Speaking ability of the student:}
a) Clear clarity with loud voice
b) Average clarity with loud voice
c) Less clarity with low voice
d) Fast with no clarity and low voice

This feature will indicate how a student can able to speak with others as well as with the teacher. This depends on the extent to which a student is having fluency over the language. If a student is strong on vocabulary of words, then he may not struggle in getting the right words during the conversation and it is very easy for him to speak fluently with a loud voice. There will be a clear cut clarity in their statements and there will be a constant delay of time between word to word and statement to statement. If a student do not having a language fluency and lack of vocabulary, then he always try to speak in low voice with lot of ambiguities, since he is not sure about himself. An average student can speak with nominal voice with average level of clarity. Some category of the students may speak in a fast way with lower voice which results in many ambiguities. There will be no delay time between word to word and statement to statement.

\subsubsection{Dressing sense of the student:}

a) Very neatly dressed with formals

b) Casually dressed with many types

c) No importance given to dresses

d) Badly dressed

This feature will indicate student's dressing sense and state of neatness. This is one of the major factors from which it can be gauged the quality of a student. Normally, above average students will wear the formal dresses by maintaining the simplicity and neatness. Some of the students may wear the dresses which will be influenced by cinema heroes or some sports persons or their role models. They are not hesitating what others will look at them and they are more worried on styles and fashions rather than academic activities. Sometimes it is very difficult to group the students based on their dressing sense, since many of the toppers may not give much importance towards their costumes, but they are giving importance to neatness. If this is the case, we need to observe their way of coming to the college both by considering their dress code as well as neatness. Some category of students may not give any importance either to dress code or to academics, but the percentage of such students is less.

\subsection{Generate dataset in Excel format :}

"Evaluation of Classroom Behavior of a Student " gives final dataset of students in a class wise by using an interface shown in fig. 4 .

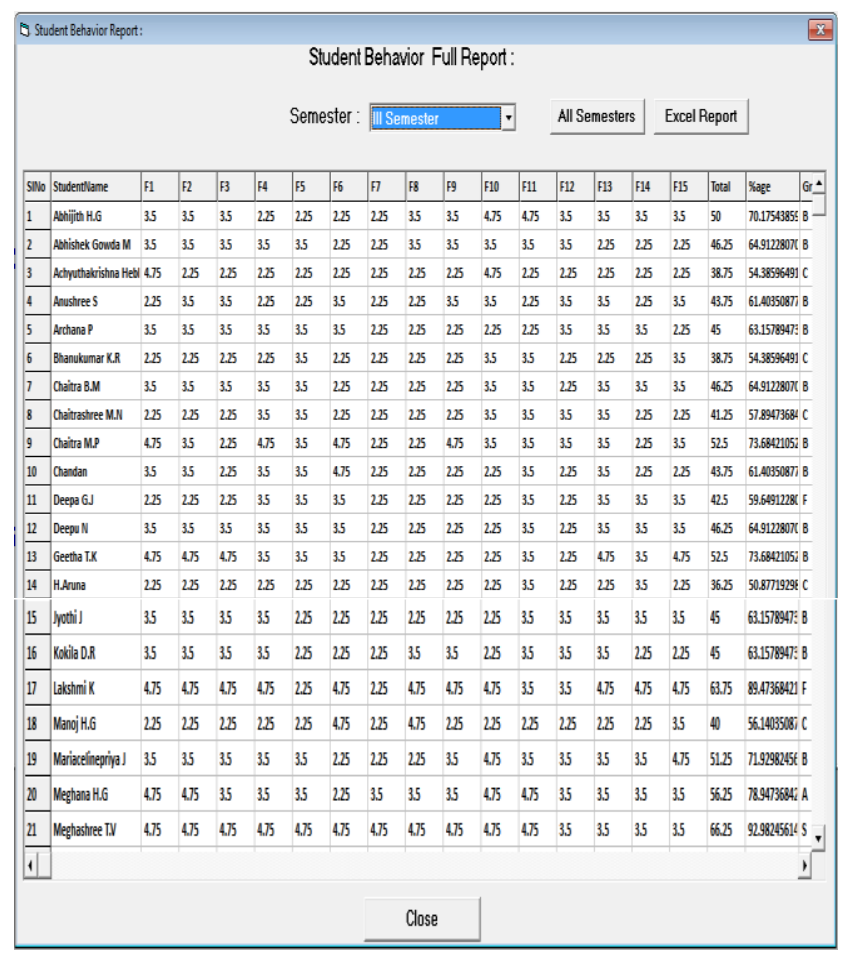

Fig.4. Interface form to list out Semester wise behavioral points of a student

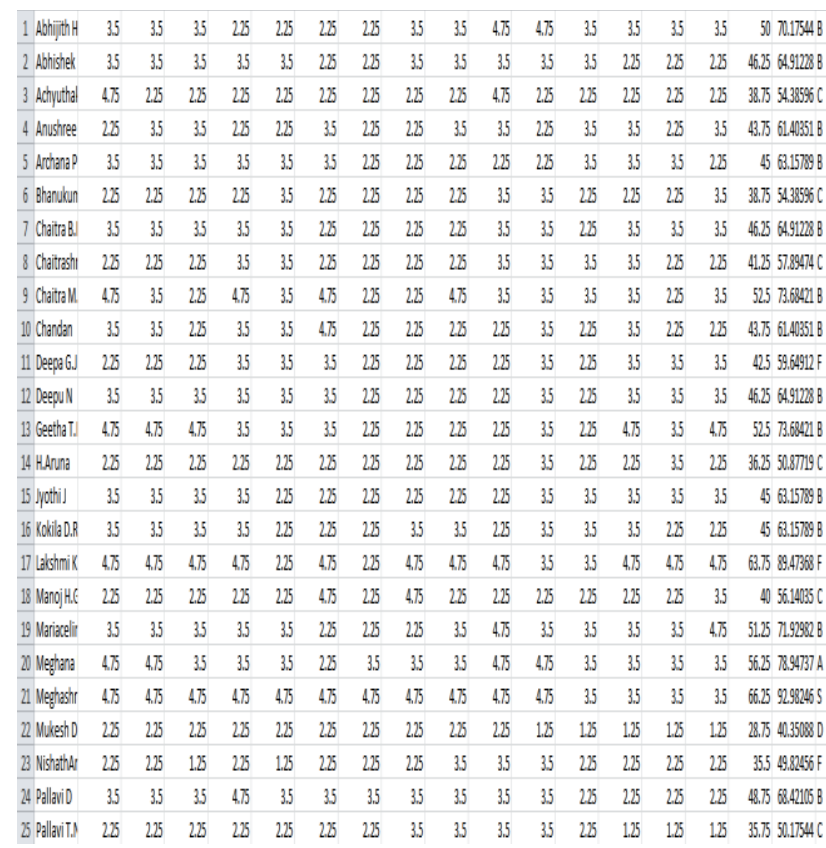

Fig.5. Generation of data set into excel format. 
With this dataset, it cannot be run directly on mat-lab tools. This needs further preprocessing of the data by generating it into excel format which was shown the fig.5.

The interface gives us the various groups of the students shown in the fig.6. Here, it is used the following decision based condition which make the student's group with the grades of A,B,C,D,F and S.

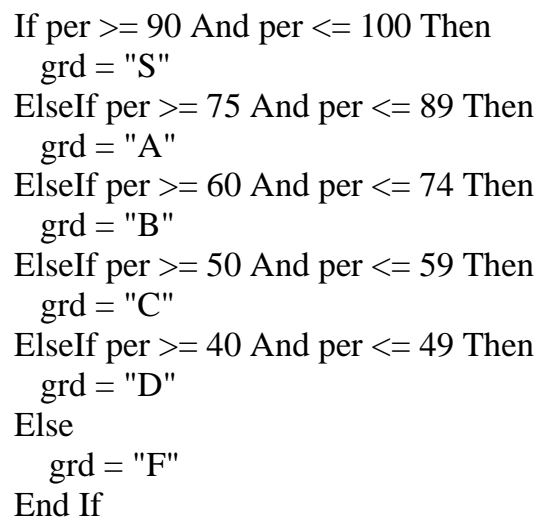

Here, per is a variable which stands for total marks and grd is a variable which stands for grade.

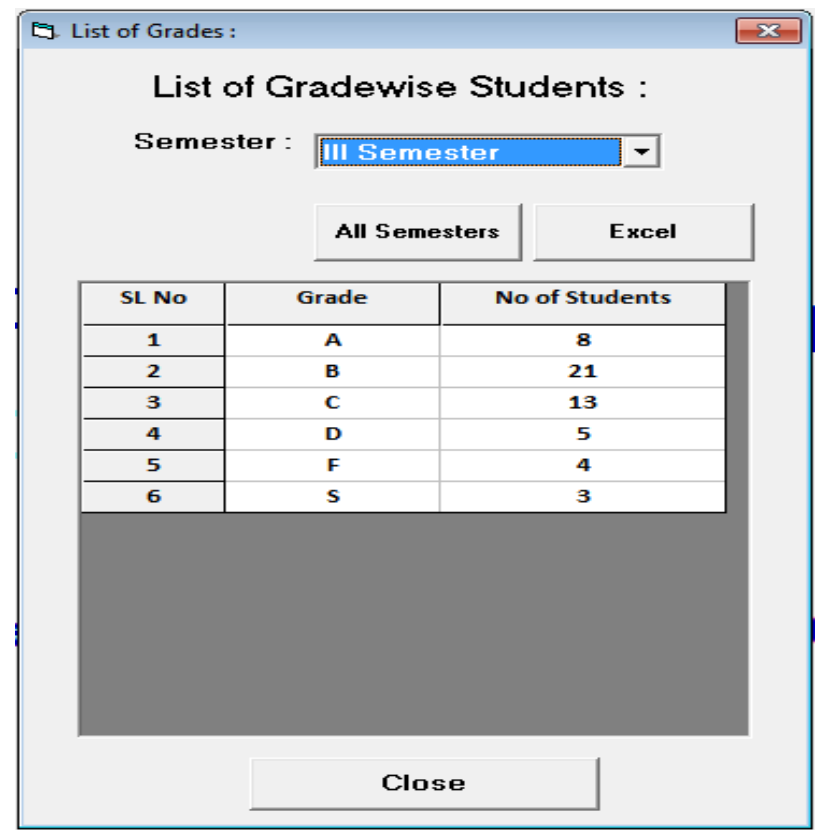

Fig.6. Interface form to list out Grade wise group of students

\subsection{Manual grouping: (Supervised grouping)}

It is necessary to make manual groups by taking range of values in a conventional way. By assuming 6 groups, it has been done by using following range of values.

i.e. Group-S is in the range of 90.0 to 100.0 ,

Group-A is in the range of 75.0 to 89.0 , Group-B is in the range of 60.0 to 74.0 , Group-C is in the range of 50.0 to 59.0 , Group-D is in the range of 40.0 to 49.0 , Group-F is in the range of 1.0 to 39.0.
This is to be done in excel sheet by using the equation:

$$
=\text { If }(\mathrm{A} 2=1,1,0)
$$

Here, A2 $\rightarrow$ is the cell number.

$1,1,0 \rightarrow$ If the behavioral points will be in the range of 90.0 to 100.0 , then it indicates that the student belongs to Group-S and 1 will be filled in the cell A2, otherwise it is filled with 0 .

$$
=\text { If }(\mathrm{A} 2=2,1,0)
$$

to fill the cell 1 if it belongs to Group-A,

$2,1,0 \rightarrow$ If the behavioral points will be in the range of 75.0 to 89.0 , then it indicates that the student belongs to Group-A and 1 will be filled in the cell A2, otherwise it is filled with 0 .

$$
=\operatorname{If}(\mathrm{A} 2=3,1,0)
$$

to fill the cell 1 if it belongs to Group-B,

$3,1,0 \rightarrow$ If the behavioral points will be in the range of 60.0 to 74.0 , then it indicates that the student belongs to Group-B and 1 will be filled in the cell A2, otherwise it is filled with 0 .

$$
=\operatorname{If}(\mathrm{A} 2=4,1,0)
$$

to fill the cell 1 if it belongs to Group-C,

$4,1,0 \rightarrow$ If the behavioral points will be in the range of 50.0 to 59.0 , then it indicates that the student belongs to Group-C and 1 will be filled in the cell A2, otherwise it is filled with 0 .

$$
=\mathrm{If}(\mathrm{A} 2=5,1,0)
$$

to fill the cell 1 if it belongs to Group-D,

$5,1,0 \rightarrow$ If the behavioral points will be in the range of 40.0 to 49.0 , then it indicates that the student belongs to Group-D and 1 will be filled in the cell A2, otherwise it is filled with 0 .

$$
=\operatorname{If}(\mathrm{A} 2=6,1,0)
$$

to fill the cell 1 if it belongs to Group-F,

$6,1,0 \rightarrow$ If the behavioral points will be in the range of 1.0 to 39.0 , then it indicates that the student belongs to Group-F and 1 will be filled in the cell A2, otherwise it is filled with 0 .

\begin{tabular}{|l|l|l|l|l|l|}
\hline G1 & G2 & G3 & G4 & G5 & G6 \\
\hline 1 & 2 & 3 & 4 & 5 & 6 \\
\hline 1 & 0 & 0 & 0 & 0 & 0 \\
\hline 0 & 1 & 0 & 0 & 0 & 0 \\
\hline 0 & 0 & 1 & 0 & 0 & 0 \\
\hline 0 & 0 & 0 & 1 & 0 & 0 \\
\hline 0 & 0 & 0 & 0 & 1 & 0 \\
\hline 0 & 0 & 0 & 0 & 0 & 1 \\
\hline
\end{tabular}

Fig.7. Manual grouping with a formation of Identity matrix.

The fig. 8 shows a solution matrix in which, first row consists of final grouping values obtained from Mat-Lab 
tool by using SOFM neural network. It is based on unsupervised learning, i.e. no human intervention is required during the learning and hardly needs to be known about the characteristics of the input data. It provides a topology preserving mapping from the high dimensional space to map units. Map units will usually form a two-dimensional lattice and thus the mapping is a mapping from high dimensional space onto a plane. The mapping preserves the relative distance between the points. Points that are near each other in the input space are mapped to nearby map units in the SOM. This SOFM architecture was run on 203 student's dataset. This will shows every student belongs to particular group.

\begin{tabular}{|l|l|l|l|l|l|l|l|l|l|l|l|l|}
\hline \multicolumn{1}{|l}{} & $\mathrm{A}$ & $\mathrm{B}$ & $\mathrm{C}$ & $\mathrm{D}$ & $\mathrm{E}$ & $\mathrm{F}$ & $\mathrm{G}$ & $\mathrm{H}$ & $\mathrm{I}$ & $\mathrm{J}$ \\
\hline 1 & 2 & 4 & 5 & 4 & 1 & 2 & 1 & 2 & 1 & 3 \\
\hline 2 & & & & & & & & & & \\
\hline 3 & 0 & 0 & 0 & 0 & 1 & 0 & 1 & 0 & 1 & 0 \\
\hline 4 & 1 & 0 & 0 & 0 & 0 & 1 & 0 & 1 & 0 & 0 \\
\hline 5 & 0 & 0 & 0 & 0 & 0 & 0 & 0 & 0 & 0 & 1 \\
\hline 6 & 0 & 1 & 0 & 1 & 0 & 0 & 0 & 0 & 0 & 0 \\
\hline 7 & 0 & 0 & 1 & 0 & 0 & 0 & 0 & 0 & 0 & 0 \\
\hline 8 & 0 & 0 & 0 & 0 & 0 & 0 & 0 & 0 & 0 & 0 \\
\hline 9 & & & & & & & & & & \\
\hline 10 & & & & & & & & & & & \\
\hline
\end{tabular}

Fig.8. Solution Matrix shows final grouping of students.

\subsection{Use of Mat-lab tool}

This is the stage where it can be used with mat-lab tools on the preprocessed dataset. The Mat-lab tool can be applied by considering 2 parameters. i) Input ii) Target

\subsubsection{Input}

This SOM has a feed-forward structure with a single computational layer arranged in rows and columns. Each neuron is fully connected to all the source nodes in the input layer. Here, the preprocessed dataset will be given to the tool for clustering process. This can be achieved by copying the dataset from excel sheet and paste them in the matrix cells provided by mat-lab tool called as Workspace cum Variable editor.

\subsubsection{Target}

Here, it has been already taken the decision regarding number of student groups. It is 6 . The values of the excel sheet will be copied and paste it in to the target workspace.

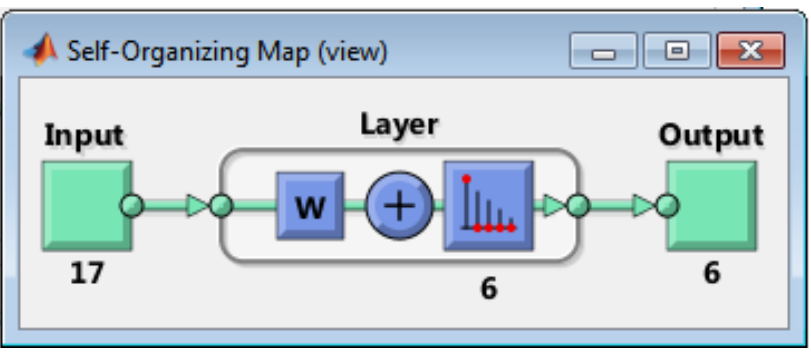

Fig.9. SOFM Neural Network architecture :

\subsubsection{Execution of the Neural network}

Following is the program run on the editor window of the MAT-Lab tool. Then it needs to run the tool and see the performance analysis.

clc;

clear all;

close all;

load StudentInput.mat

$\mathrm{x}=\mathrm{INPUT}$;

$\%$ Create a Self-Organizing Map

dimension $1=3$;

dimension $2=2$;

net $=$ selforgmap $([$ dimension 1 dimension 2$])$;

$\%$ Train the Network

$[$ net,tr] $=\operatorname{train}($ net,$x)$;

$\%$ Test the Network

$\mathrm{y}=\operatorname{net}(\mathrm{x})$;

$\%$ View the Network

$\operatorname{view}($ net)

\subsubsection{Evaluation of the output: SOM Topology}

Here, it is necessary to check the output of the SOFM NN architecture with the manual grouping results. This can be done by checking plotsomtop .i.e. SOM Topology which is shown is Fig.10.

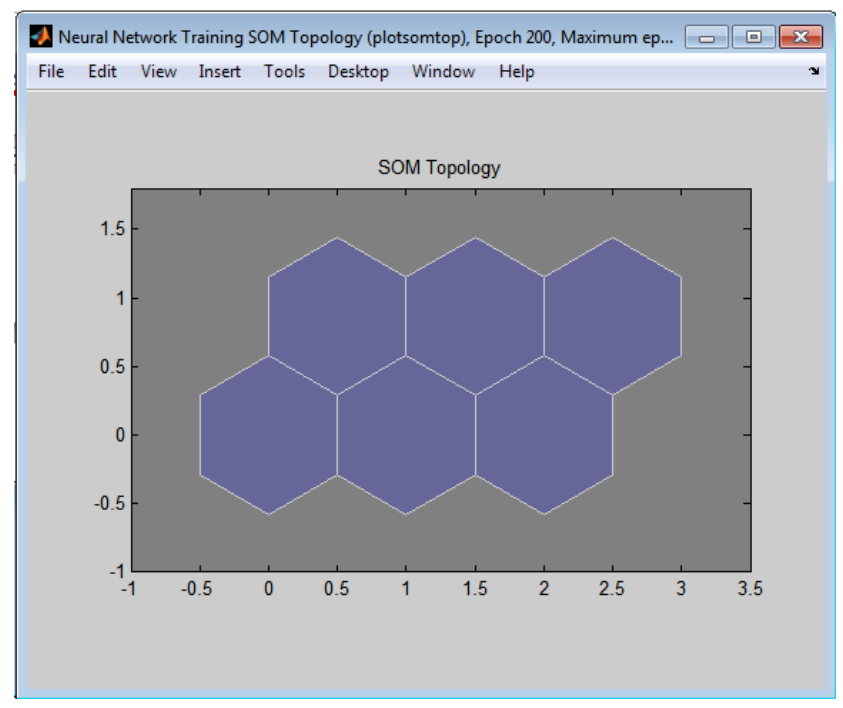

Fig.10. SOM Topology (plotsomtop) :

a) Ordering or self-organizing phase - In this phase, the topological ordering of the weight vectors takes place by taking as many iterations and careful consideration needs to be given to the choice of neighbourhood and learning rate parameters.

b) Convergence phase - In this phase, the feature map is fine-tuned and comes to provide an accurate statistical quantification of the input space. The number of iterations in this phase will be at least 500 times the number of neurons in the 
network, and again the parameters must be chosen carefully.

\subsubsection{NN Training SOM Weight Positions (Plotsompos)}

The output nodes map to points in the input space. Random initial weights start the circles at random positions in the centre of the input space. The closest output point represents the winning neuron. That winning neuron is moved towards the data point by a certain amount, and the two neighbouring neurons move by smaller amounts.

By looking into the fig.11, 6 circles were formed which indicates six groups which are scattered almost linearly with varied positions.

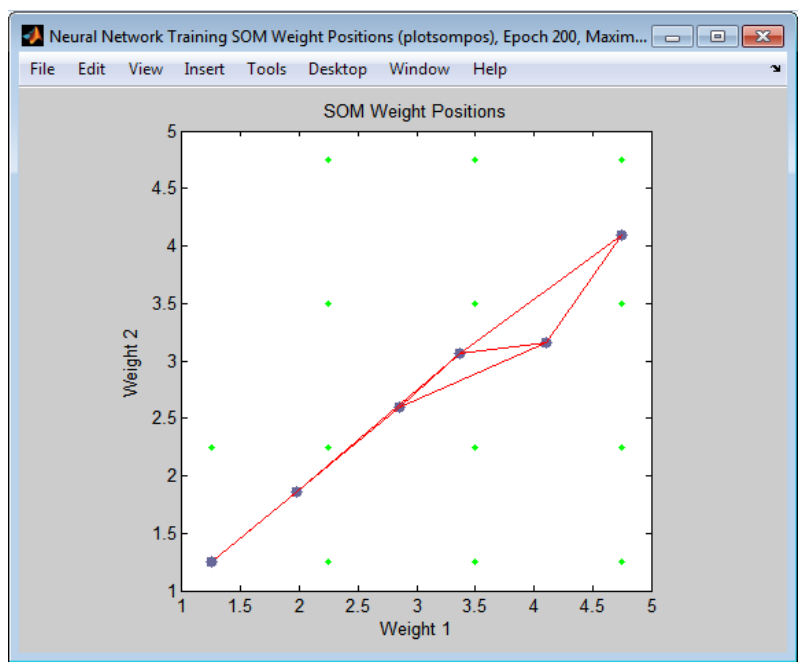

Fig.11. NN Training SOM Weight positions (plotsompos)

\subsubsection{NN Training SOM Neighbor Connections (Plotsomnc)}

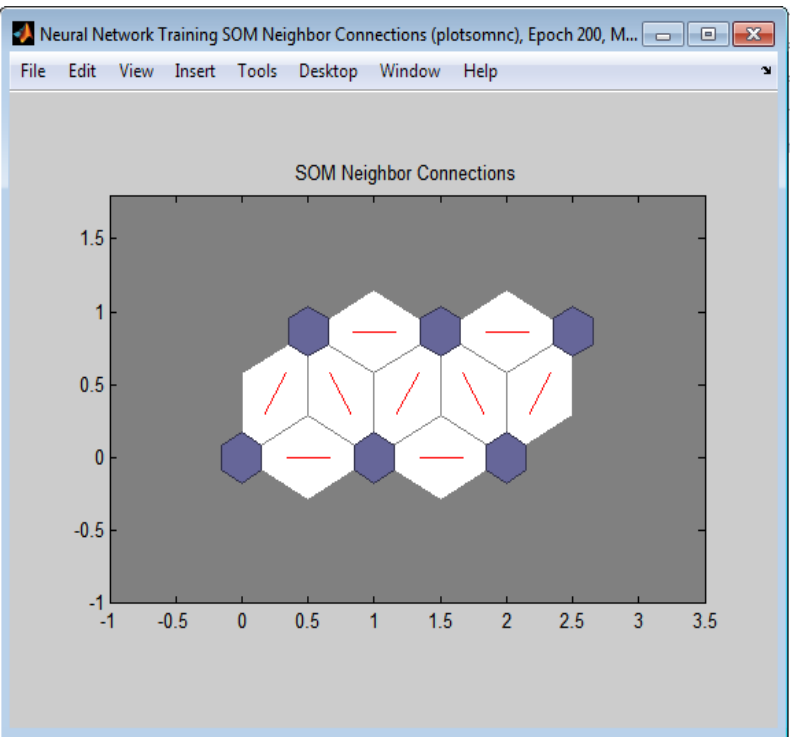

Fig.12. NN Training SOM neighbor connections (plotsomnc)
Here a SOFM network identifies a winning neuron $i^{*}$ using the procedure as initiated by a competitive layer. Instead of updating only the winning neuron, all neurons within a certain neighborhood $N_{i^{*}}(d)$ of the winning neuron are updated, using the Kohonen rule. Specifically, all such neurons $i \in N_{i^{*}}(d)$ are adjusted as follows:

$$
i \mathbf{w}(q)={ }_{i} \mathbf{w}(q-1)+\alpha\left(\mathbf{p}(q)-{ }_{i} \mathbf{w}(q-1)\right)
$$

or

$$
i \mathbf{w}(q)=(1-\alpha) i \mathbf{w}(q-1)+\alpha \mathbf{p}(q)
$$

Here the neighborhood $N_{i^{*}}(d)$ contains the indices for all of the neurons that lie within a radius $d$ of the winning neuron $i^{*}$.

$$
N_{i}(d)=\left\{j, d_{i j} \leq d\right\}
$$

\subsubsection{Final result:}

Table 1. Final Group of students.

\begin{tabular}{|l|l|l|l|l|l|}
\hline A & B & C & D & F & S \\
\hline 51 & 85 & 25 & 16 & 17 & 9 \\
\hline
\end{tabular}

The table 1 shows the final group of students obtained from SOFM algorithm by applying on 203 students in which it has formulated with 6 groups. Here, group-S has got 9 students who are seems to be top graded students who can able to score the marks in the range of above 90 , group-A has got 51 students who seems to be above average students who can able to score the marks in the range of 75 to 90 , group-B has got 85 students who seems to be good average students who can able to score the marks in the range of 60 to 75 , group-C has got 25 students who seems to be average students who can able to score the marks in the range of 50 to 60 , group-D has got 16 students who seems to be below average students who can able to score the marks in the range of 40 to 50 , group-F has got 17 students who seems to be slow learners who cannot able to score even pass marks. This is result obtained from SOFM algorithm.

\subsubsection{Bar Chart based on final groups:}

A Bar Chart is a graphical representation of the distribution of numerical data in the form of bars. It is a chart or graph that represents categorical data with rectangular bars with heights or lengths proportional to the values that they represent. It shows comparisons among discrete categories. One axis of the chart shows the specific categories being compared, and the other axis represents a measured value.

Here, $\mathrm{Y}$-axis represents number of students and $\mathrm{X}$-axis represents name of the groups. 


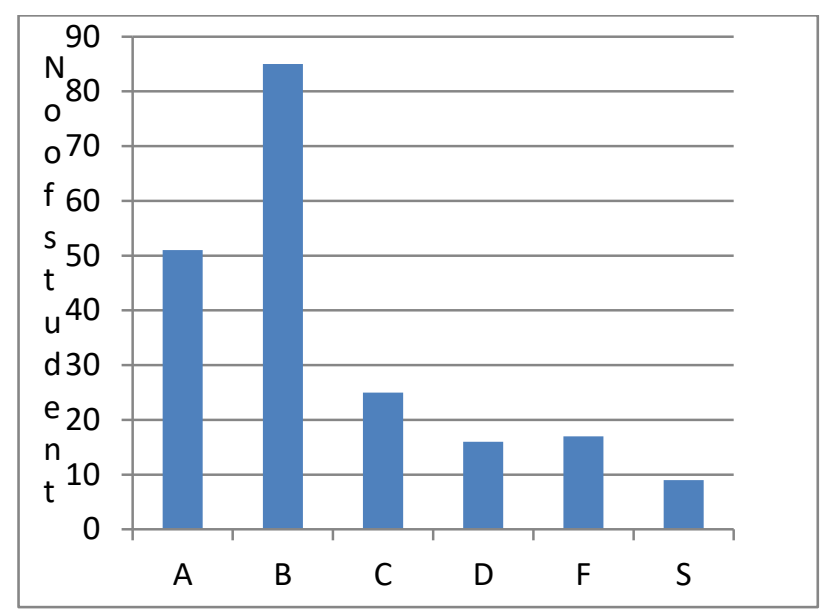

Fig.13. Bar-Chart showing final group of students:

\subsubsection{Grouping thru Program: (Manual grouping)}

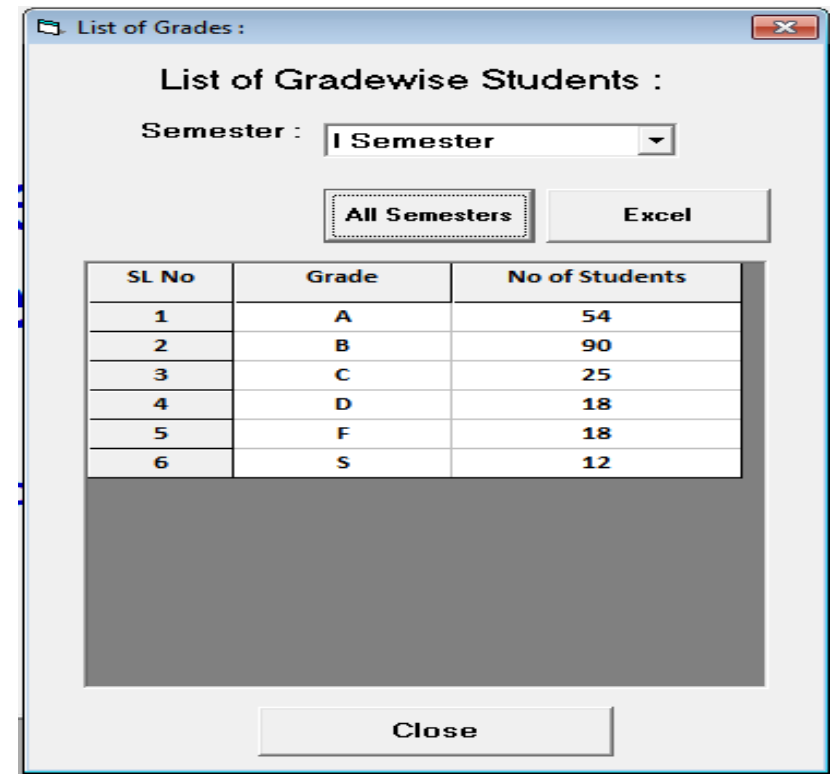

Fig.14. Interface showing final group of students: (Manual grouping thru program)

The fig.14 shows the interface in which it shows the final group of students obtained from program written in VB.Net thru MS Access database. According to this, group-S has got 12 students, group-A has got 54 students, group-B has got 90 students, group-C has got 25 students, group-D has got 18 students and group-F has got 18 students. This is the result obtained among the dataset of 203 students.

\subsubsection{Result analysis between manual method and Soft computing method (SOFM algorithm)}

By looking in to the results of table-1 and fig.14, it is found that, the groups obtained from SOFM algorithm is almost similar to manual groups. Even though there are slight changes in the values of various groups, the difference value is almost minimum. SOFM algorithm has given group-S with 9 students, group-A with 51 students, group-B with 85 students, group-C with 25 students, group-D with 16 students and group-F with 17 students. Whereas manual grouping has given group-S with 12 students, group-A with 54 students, group-B with 90 students, group-C with 25 students, group-D with 18 students and group-F with 18 students.

\section{CONCLUSION}

There was an attempt made on the various behavioral patterns of the graduate students to identify group of bright students based on their level of understanding capability, learning speed, thinking ability, writing ability, way of approach with others, quality of communication and analytical skills. Here, instead of going with traditional methods like marks scored in internal tests, midterm examinations, final exams we have considered other informal and unique approaches. We have considered their class room behaviors and campus behaviors when they are in classrooms and college campuses. There has been close monitoring of nearly 200 + students over a span of 4 to 6 months and all these students are presently studying in an engineering college. This approach was implemented both by using manual method and soft computing techniques and at the end we have compared their results in the form of groups. There were slight differences in the result sets. This is an indication that we have reached a positive approach. Anyway, even though, we got the practical justification from these methods, we cannot confidently say that this will work out with all type of students and all types of institutions. We can say that, this is one of the sincere and prominent attempts made in this regard, so that we can say that this also seems to be one of the informal ways of identifying bright students. Still lot of scopes will be there to improve this approach by working with other algorithms and other methods. We will highly appreciate your valuable feedbacks in the form of suggestions and improvements.

\section{REFERENCES}

[1] Josephine Infantino \& Emma Little : "Students' Perceptions of Classroom Behaviour Problems and the Effectiveness of Different Disciplinary Methods" - The Journal of Education Research, Pages 491 - 508, published online on 19 January 2007.

[2] Edmund T. Emmer \&Laura M. Stough "Classroom Management: A Critical Part of Educational Psychology, With Implications for Teacher Education" - Journal : Educational Psychologist, Volume 36, Issue 2. Pages 102 - 112, published online on 08 June 2010.

[3] Leslie C. Soodak "Classroom Management in Inclusive Settings" - Journal : Theory Into Practice, Volume - 42, Issue - 4, Pages 327 - 333 Published online 24 June 2010.

[4] Paul Black \&Dylan Wiliam "Assessment and Classroom Learning" - The Journal of Education Research, Pages 7 - 74, published online on 28 July 2006.

[5] Karin Barac, Marina Kirstein, Rolien Kunz, Bernice Beukes "Factors influencing students' learning approaches in auditing" - Journal : The Journal of Economic Education, Volume - 23, Issue 23, Published online on 15th July 2014.

[6] Joyce Phikisile Dhlamini "Management of Learner Discipline in Secondary Schools: A Collaborative 
Effort"- International Journal of Educational Sciences, Volume 15, 2016 - Issue 3 Published online 25 Sep 2017.

[7] Md. Saiful Malak, Umesh Sharma \& Joanne M. Deppeler "Predictors of primary school teacher's behavioural intention to teach student's demonstrating inappropriate behaviour in regular classrooms" - Cambridge Journal of Education, Published online 04 Sep 2017.

[8] Sue Catherine O'Neill \& Jennifer Stephenson "The measurement of classroom management self-efficacy : a review of measurement instrument development and influences ", - Educational Psychology, Volume 31, 2011 - Issue 3, Published Online: 02 Feb 2011.

[9] RobynBeaman, Kevin Wheldall \& Coral Kemp "Recent Research on Troublesome Classroom Behaviour : A Review", Australasian Journal of Special Education, Volume 31, 2007 - Issue 1, Published Online: 26 Sep 2007.

[10] Dr.R.B.V.Subramanyam and A.Goswami : "A Fuzzy Data Mining Algorithm for Incremental Mining of Quantitative Sequential Patterns " - International Journal of Uncertainty, Fuzziness and Knowledge-Based systems, Vol-13, No-6, 2005, 633-652

[11] Powers, David M W (2011). "Evaluation: From Precision, Recall and F-Measure to ROC, Informedness, Markedness \& Correlation" (PDF). Journal of Machine Learning Technologies 2 (1): 37-63.

[12] Jiabin Deng, JuanLi Hu, Hehua Chi : "An Improved Fuzzy Clustering Method for Text Mining “ $-2^{\text {nd }}$ International Conference on Network Security, Wireless Communications and Trusted Computing", 978-0-76954011-5/10@ 2010 IEEE

[13] Timothy C.Havens, James C.Bezdek, Marimuthu Palaniswami : "Fuzzy c-Means Algorithms for Very Large Data "IEEE Transactions on Fuzzy Systems, Vol20, No-6, December - 2012.

[14] Junli Lu, Lizhen Wang, Yaobo Li :" A Fuzzy Clustering Method Based on Domain Knowledge" $-8^{\text {th }}$ ACIS International Conference on Artificial Intelligence. 07695-2909-7/07 IEEE

[15] Saeed. R. Aghabozorgi, The Ying Wah : "Using Incremental Fuzzy clustering to Web Usage Mining “, International Conference of Soft Computing and Pattern Recognition, 2009 of Master of Computer Applications, Siddaganga Institute of Technology, Tumkur, Karnataka. Currently, he is pursuing his Doctor of Philosophy work at Research Centre, Department of Computer Science and Engineering, SIT, Tumkur of Visveshvaraiah Technological University, Belgaum. in the field of soft computing techniques with database applications and data mining applications.

His areas of specialization include design and development of database applications, Advanced Operating systems, Neural networks, Data Mining and other Soft Computing Techniques.

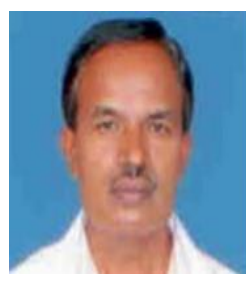

Y.S. Nijagunarya., received B.E. from Bangalore University, M.Tech from University of Mysore, and Ph.D. from University of Mysore.

Dr. Y.S. Nijagunarya has 32 years of teaching and 12 years of research experience. Presently he is working as Professor, in the department of Computer Science and Engineering, Siddaganga Institute of Technology, Tumkur. Currently he is guiding four research scholars.

His areas of specialization includes Soft Computing Techniques, Neural Networks and Fuzzy Logic.

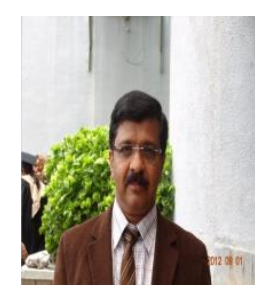

M.A.Jayaram., received $\mathrm{BE}$ from Bangalore university, M.Tech from NIT(K), Surathkal, MCA(IGNOU), and $\mathrm{PhD}$ from VTU, Belgaum, Karnataka. Dr.M.A.Jayaram has 32 years of teaching and 13 years of research experience.

Authored 12 Books and more than 100 reasearch papers in National/ International Journals and conferences. Areas of specialization includes, digital image processing, soft computing, data analytics and algorithmic problem solving. Has guided one reasearch scholar and currently guiding three research scolars. Is a member in editorial team of several reputed International Journals.

\section{Authors' Profiles}

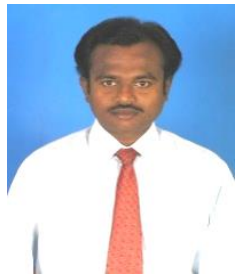

C.Bhanuprakash, received the B.E.in Mechanical Engineering and Master of Computer Applications degrees from Siddaganga Institute of Technology, Tumkur, of Bangalore University, in 1993 and 1998, respectively.

C.Bhanuprakash has 17 years of experience in Teaching, 4 Years of Industry experience and 4 years of research experience. Presently he is working as Assistant Professor in the department
How to cite this paper: C.Bhanuprakash, Y.S. Nijagunarya, M.A. Jayaram, " An Informal Approach to Identify Bright Graduate Students by Evaluating their Classroom Behavioral Patterns by Using Kohonen Self Organizing Feature Map ", International Journal of Modern Education and Computer Science(IJMECS), Vol.10, No.8, pp. 22-32, 2018.DOI: 10.5815/ijmecs.2018.08.03 